\title{
Governance in Dutch hospitals
}

\author{
R.M.A. (Ron) van der Pennen ${ }^{1,2}$, H.J.J.M. (Bart) Berden ${ }^{2,3}$, E.C.A. (Eveline) Castelijns ${ }^{4}$, W.L. (Wouter) Vreeman ${ }^{3}$ and Th.W.A. \\ (Theo) Camps $^{2,4}$ \\ ${ }^{1}$ Rivas Zorggroep, Banneweg 57, 4204 AA Gorinchem, The Netherlands \\ ${ }^{2}$ TiasNimbas Business School, University of Tilburg, Warandelaan 2, 5037 AB Tilburg, The Netherlands; \\ r.m.a.vdrpennen@tiasnimbas.edu \\ ${ }^{3}$ St. Elisabeth ziekenhuis, Hilvarenbeekseweg 60, 5022 GC Tilburg, The Netherlands \\ ${ }^{4}$ Berenschot BV, Europalaan 40, 3526 KS Utrecht, The Netherlands
}

\begin{abstract}
In this article we have characterised Dutch hospitals as organizational networks. They operate in a blurred context, which is the interference of principles from market and hierarchy. Based on these principles we questioned the optimal way governance can be organised. The context for governance is explained along two pathways: First, specific issues of the Dutch healthcare system and current trends in society force hospitals to react and respond in a certain way. Second, the typical organisational position of physicians in Dutch healthcare makes governance a challenge. In this context one can look at governance twofold: control or learn. We argue that each type of risk should be countered with the best applicable instrument. This means, that control or learn never can be the only convenient governance instrument. The board's choice for the proper action therefore is always ambivalent. However, the profound role of control and the neglected role of learning principles is obvious. Notwithstanding the effectiveness of control in certain situations, we recommend more attention for the possibilities and value of a learning governance view. Furthermore, we denote that such a learning environment comes from a trust-built relationship. Network participants should open up more, en should be encouraged to give each other feedback. In the hospital setting this means physicians and board members should have personal qualities in terms of empathy and sensitivity.
\end{abstract}

Keywords: trust, organisation, health care, physicians

\section{Introduction}

In January of 2009, it became publically known that a neurologist at the Medisch Spectrum Twente Hospital (MST hospital) had been issued to leave this hospital in 2003 due to malpractices. The concerning medical specialist would have incorrectly diagnosed his patients and unjustly prescribed hazardous medication. Despite these observations, the neurologist was able to leave the hospital unperceived and with a proper departure settlement. It is not until the announcement that the same neurologist is working in a hospital in Germany that this case draws national media attention. The impression of a wide spread cover-up soon. The MST hospital had been aware of the malfunctioning of the neurologist for quite some time, but had intentionally made attempts to cover this up. The current Board of Directors at the MST hospital issued an independent investigation to bring transparency to this matter. Results indicated that the neurologist in question operated independently from his peers, did not keep patient records in a proper way, misdiagnosed his patients, prescribed risky medication, ordered unrestrained examinations and thus causing, often irreparable, damage to patients. This damage would have been less extensive if the direct colleagues of the neurologist, the Board of Directors as well as the National Healthcare Inspectorate had taken responsibility for good quality of healthcare.

The case above presents a real life illustration of the complexities that influence the daily operations and governance of a Dutch hospital. All the internal affairs initially were managed carefully and secretly. Simultaneously the outside world changed rapidly and demanded not only attention but also accountability. This caused serious questions about the way the case was dealt with. Considering this specific case, the outside world expected the board to have prevented this malpractice, to avoid these kinds of mistakes and probably to terminate the situation by sending the medical specialist away in a much earlier phase. Most of the time these expectations are directly related to public expectations, beliefs and values. However, these public beliefs and values do not automatically meet organizational and professional ones. In case of hospitals, the multidimensional complexity of the organisation makes the publicly assumed interventions not always possible or applicable. The case of MST hospital illustrates that governance in the context of Dutch hospitals is far from 
simple or linear. It is dynamic, complex and continuously changing.

Because of the gap between reality in hospitals and the expectancies it is not surprising that the governance of hospitals has become a much discussed topic amongst healthcare managers, professionals, politicians and also the media. An immense task that has become even more pregnant since healthcare reforms of 2006 introducing market mechanisms at the expense of bureaucratic steering. The central question therefore in this article is:

'How can hospitals optimally organise their governance (effectively manage, control, take responsibility and account for their actions), taking into account the complex field and context in which hospitals operate?'

The interaction between inner and outer world is complex and challenges the way in which governance is organised in the Dutch healthcare sector. In the first two parts of this paper we focus on governance and networks. The third part contains a description of the Dutch system including the recent healthcare reforms in the Netherlands. This demonstrates the recent changes and is the basis for the way governance is organised. Further, we elaborate on the necessity of adequate governance within hospitals. This will be done by the introduction of a risk classification and a specific view on governance instruments. We will round off the article by answering the central questions stated in the introduction.

\section{Governance}

Jessop (2003) defines governance as 'the reflexive selforganization of independent actors involved in complex relations of reciprocal interdependence, with such selforganization being based on continuing dialogue and resource-sharing to develop mutually beneficial joint projects and to manage the contradictions and dilemmas inevitably involved in such situations.'

In other words: governance is about interaction for control, supervision, justification, accountability and responsibility between all actors involved. The basic assumptions of governance can be seen as someone who 'manages', while at least someone else at the same time must have insight in these managerial activities and be able to influence them. In short, governance can be defined as the scheme of morals and rules of conduct for management, control and accountability.

A recent study of the Dutch Health Care Inspectorate (IGZ, 2009) gives a useful framework for governance. The aim of governance in this study is defined as to create public confidence in the organisation's processes, products and services. The framework is built upon five elements (Figure 1):

- Professionals should have operational responsibility and therefore are in charge of setting norms of quality of processes, products and services. To do so adequately, the oath of Hippocrates is their guide. Professionalism is also about cooperation and openness and is based upon good education. The openness also implies that clients, colleagues and members of the board may question the professional about quality of care.

Goal

\section{Justified trust in responsible health care}

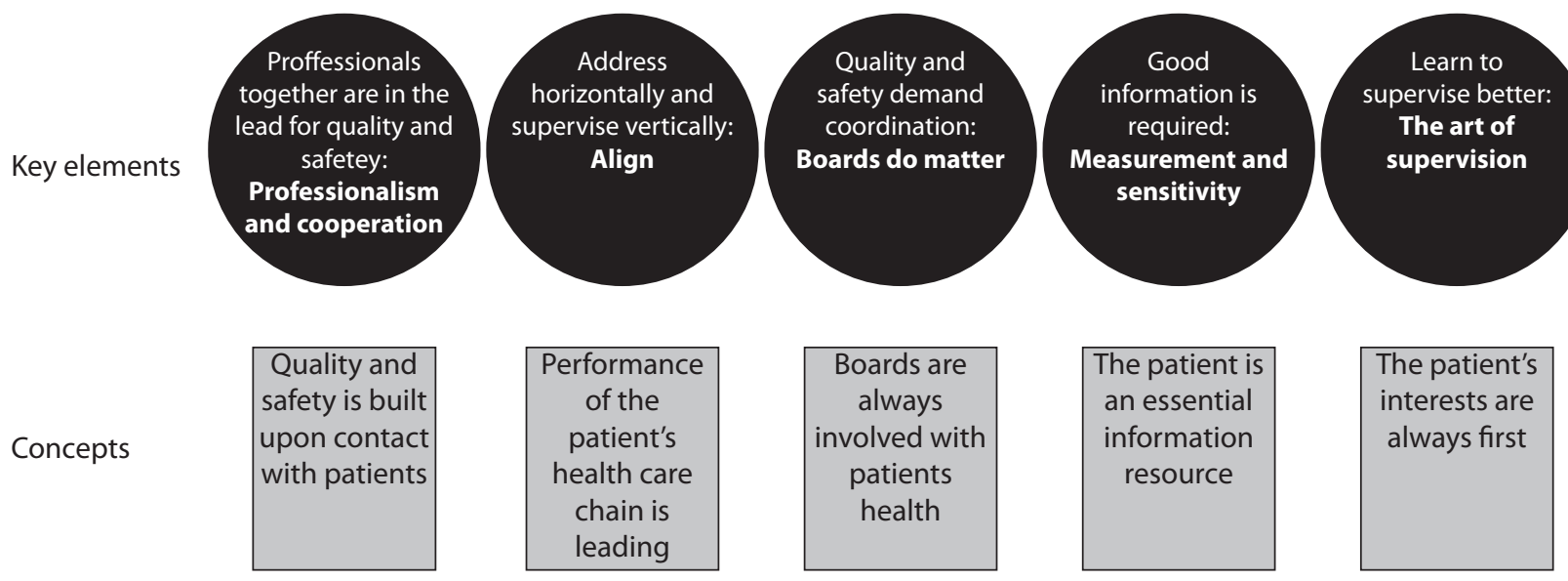

Figure 1. Justified trust (IGZ, 2009). 
- Clients are always benchmark for quality and 'good organisation'. This implies that horizontal and vertical supervision between all actors involved must take place. In addition, the relationship between organization's boards, managers and professionals should be reconsidered. In order to do so, each function's description and its responsibilities should be clear and defined. Besides that, one should respect differences and show respect for each other's responsibilities.

- Although professionals set standards, the management/ board level must be committed to these and make sure these standards are broadly accepted and can be held accounted for. Their role in this is vital. At the end the board is responsible and must be willing to account for this final responsibility.

- The organization of governance can not do without accurate information. This information is used for several meanings: (organizational) learning, setting standards, encouragement and accountability. The patient is vital for this information. For example, think about the feedback information about treatment and stay in a hospital. In case of quality and the responsibility for quality, this specific information from a patient perspective enlarges qualitative and quantitative knowledge.

- The final element is related to supervision. Proper and effective supervision, in which the client's central position is vital, is a learning process. In this, the art and the knowledge of supervision are crucial, as well as the fact that quality is on top of the policy-agenda.

What figures strongly from these five elements are the network elements in it. Different actors in the governance system en processes should cooperate, should be keen on ones norms and standards, and also should create a learning climate. Most of all, the IGZ stresses that certain roles and responsibilities should be clearly defined, which should make role setting relatively easy. Physicians and managers cooperate intensively although both have different responsibilities and tasks. Besides, this implies a mutual acceptance of each of these roles. In the next part we focus more on networks and its characteristics.

\section{Networks}

As we will describe later, hospitals can be defined as networks. The given vision on governance by the Dutch Inspectorate also shows this. Multiple actors each have a share in the total organizational responsibility. From a view of countervailing power this shared responsibility at least results in some kind of equilibrium. John Kenneth Galbraith first introduced the term 'countervailing power'. (Galbraith, 1963). Although it may seem a negative instrument, in fact countervailing power is a positive instrument to achieve and retain a desired situation in a complex system (RVZ, 2008). In other words, countervailing power in a network results in a certain equilibrium. This equilibrium can either be stable or dynamic.

Because the network view is crucial in the forthcoming parts of this paper, we first take a closer look at organizational networks.

\section{Organizational networks}

In a society that increasingly demands more transparency and accountability, the usual systems and structures are not giving answers that satisfy these demands. Public and private systems have shown not to match the demands. We therefore try to focus on governance form a network perspective.

Organizational networks imply freedom, self-control and openness. Most of the time the advantages of these networks are efficiency, innovation and a learning culture. However, organizational networks are able to provide a qualitative better product or service (Broekman and Camps, 2006). Let us look a little bit closer to the way the networks are managed or guided. Of course, this is diverse. However, Broekman and Camps (2006) appoint four elements that influence the choice made in network management:

- the number of network participants;

- the degree to which tasks can be refined into subtasks;

- organizational competences;

- the degree to which the participants agree over network goals and values.

The management of networks can, dependent on these factors, vary from self management to management by one participant. Besides the common network goals, all participants also have their own agenda and their own goals. These different goals, the shares of responsibility and the countervailing power, make the network complex and dynamic. It results in a network equilibrium, that is unstable and therefore makes the choice in type of management disputable. In the network all kinds of tension rise, also as a result of individual diverging goals, and thus in the management of it. It is common that this tension is caused by opposite meanings on efficiency versus effectiveness, flexibility versus stability, etc. Another main disputable point in networks has to do with the internal and external legitimacy. What is good for the network does not automatically mean, that it is good for each individual participant as well. How these network issues are being managed is also dependent on the former four elements. We already have denoted why networks can give a new perspective on transparency and accountability. It is for sure that market and hierarchic principles have their advantages. 
But both also have their negative sides. Therefore the network structures can add a new perspective, although we have to be honest and denote some possible network failures as well.

Organizational networks are often built to gain efficiency. However, it is common for networks to fail, because they do not sustain when resources are scarce and the individual goals of each network participant are at stake. Therefore the prisoner's dilemma is an important element in networks. This dilemma makes that partnership in networks are always in conflict with trust. Second and in addition to the prisoner's dilemma, individual participants of a network face another, intrinsic, dilemma. 'On the one hand cooperative arrangements presuppose confidence... On the other hand, confidence presupposes cooperation.' (Schrank and Whitford, 2007). A third element of network failure has to do with the way commitment is secured. In networks the efforts to gain and maintain commitment are high. To foster innovation and gain efficiency, networks should be able to build in cooperation and confidence and make sure individual and network goals are aligned. When one of these elements fails, network failures occur and make networks less effective and efficient in realizing their goals.

\section{Interfering guiding principles}

Although the network structure can add a new perspective, each individual participant also has its own guiding principles. Therefore market and hierarchy (bureaucratic) principles are also involved in network situations.

These principles also interact, which makes network organizations in time complex and dynamic. This interaction is referred to as blurring (Van der Wal et al., 2007; Van der Wal and Van Hout, 2009). For several years, private values have entered the public domain. An example for this is the market orientation introduced in the Dutch health care sector. Public and private values, and also specific network values, interact and form the framework for operations to work in. When referred to blurring one should take into account that different types of blurring exist (Van der Wal and Van Hout, 2009):

- The first type emphasizes the opposite and incompatible differences between values of different sectors (public, private, etc.).

- The second type is called bridging: it recognizes the differences in ethical standards of each sphere (public, private, etc.) and face it positively.

- "The third group emphasizes similarities and stresses that the same moral criteria and values can (or even should) be applied to all kinds of organizations.' (Van der Wal et al., 2007; Caiden 1999).
The main point that follows from blurring, is that it in particular determines the context for the healthcare system at an abstract level. Problematic however is that the values that correspond with each of these principles often are contradictory. As said before, the introduction of a market orientation in hospitals made hospital boards and professionals focus on efficiency. However, the goals following from this guiding principle do not align easily with public values and goals like solidarity and affordability. Besides the contradiction of certain values and morals, each guiding principle also has its own failures as a result of their imperfections. These failures also have to be taken into account.

\section{Market failure}

Market failure occurs when, as a result of a market's imperfection, it fails to achieve an optimum solution. Often the cause for this failure is the existence of fundamental external factors, for instance imperfect competition. The existence of a market failure is often used by government as a justification for intervention in a particular market, such as the healthcare sector in the Netherlands.

\section{Hierarchy failure (bureaucratic or government failure)}

A government intervention implicates caring for public values. However, it is common that a negative side effect occurs. Government interventions for public values, lead to a less efficient allocation of products or services, which clearly is a market principle goal. Although the government is able to realize a stable outcome, it does have a negative effect on the efficiency of the market. Allocation from the public sector does not take into account the proportions between costs and turnovers.

The described blurring of principles and also the failures that occur, effect the network organisation. This is because the values of the three principles intertwine and most of the time are opposite to each other. The failures amplify this effect. From a governance perspective, it is not always easy to explain why certain choices were made in favour of market values, while in the meantime this choice affects a public value. This situation is even stronger because each of the principles also has its own representative in the 'governance circle' of a hospital. That is why pressure will be firm. It is blurring that - as a context - defines the degree of efficiency, effectiveness and sustainability that healthcare organizations can arrange. In other words, the interaction creates the framework for organizations to act and to organize their governance.

As will figure from our following description of the Dutch health care system, the blurring of principles and their 
failures also applies to the context of Dutch healthcare institutions, more specific in hospitals. The market principle and failure occurs in the market of purchasing care. The insurer and the healthcare provider set the price for the delivery of healthcare. However, the national government in the Netherlands intervenes in this relation. The hierarchy principle is wide spread in healthcare due to public values that merge with healthcare. The government, for instance, sets the standards for quality and safety. The network and its failures are also common for the Dutch healthcare sector. Providers of cure and care, government organizations, insurers and other stakeholders, such as NGO's, patients, consumer federations and medical specialists all together form the healthcare networks in the Netherlands.

\section{Hospital organization as a network}

Hospitals are typical examples of third sector organizations. Typical elements of these organizations are solidarity, responsibility, but most of all reciprocal responsibility. (Van de Donk, 2001; Van Hout 2007) Referred to networks one can easily say that hospitals are more and more network participants. Hospitals increasingly work together with other organizations. Several examples underpin this statement. Due to several changes in the system, hospitals focus more and more on their duty to provide healthcare. This means that hospitals have and will become more specialized. While the care part also was a main task of hospitals, e.g. after surgery, developments show that these tasks are being replaced to other care providers. It is even more common that care is replaced to the patient's home setting, where other organizations can provide home-care.

Another development has to do with patients' demands. Due to specialization the patient value chain could get fall apart into loose parts. However the patient wants his chain to be efficient as well as effective. This notice aligns with the governance model by the National Healthcare Inspectorate. Related to the possible rise of the tension network, one can imagine that the internal and external legitimacy of a hospital network does not always align with all actors. Does the board focus above all on the hospital's values or on the values of the patient health care chain? And how do they respond to the family doctor's demands in the chain? Having denoted the hospital as a network participant or a network organization, a closer look at the Dutch healthcare system is given, before the aspect of governance will be described.

\section{The Dutch healthcare system}

As mentioned in the introduction the Dutch healthcare system is complex. This has, partly, to do with the fact that the 'Dutch health care institutions have been 'reorganized', 'restructured' and 'reinvented', in order to cope with new demands, constraints and choices' (Noordegraaf et al., 2005). The improvement of quality and safety and controlling the rising costs were the important challenges, which induced this. However the public values as solidarity, accessibility and affordability in healthcare should also withstand.

To get a better picture of the current situation in the sector we will elaborate on the system, the way hospitals in The Netherlands are organised, future demands on healthcare, the reforms that have been introduced to counter-pressure these demands and the consequences of these on hospitals and the medical specialists.

\section{The system}

The Dutch health care system can best be described as a triangular system. Each side of the triangle stands for one part of the total system. That gives three sides that reflects three submarkets (Figure 2):

- The healthcare insurance market: the relationship between the insurer and the patient (all residents are obliged to take out a basic health insurance).

- The market of purchasing care: the relationship between the insurer (as the dominant buying party) and the healthcare provider.

- The care delivering market: the relationship between the healthcare provider and the patient.

One crucial remark has to be made. The role and the position of the government are not reflected in the figure. The government however is involved in the system by setting a framework for the playing field. Besides that the

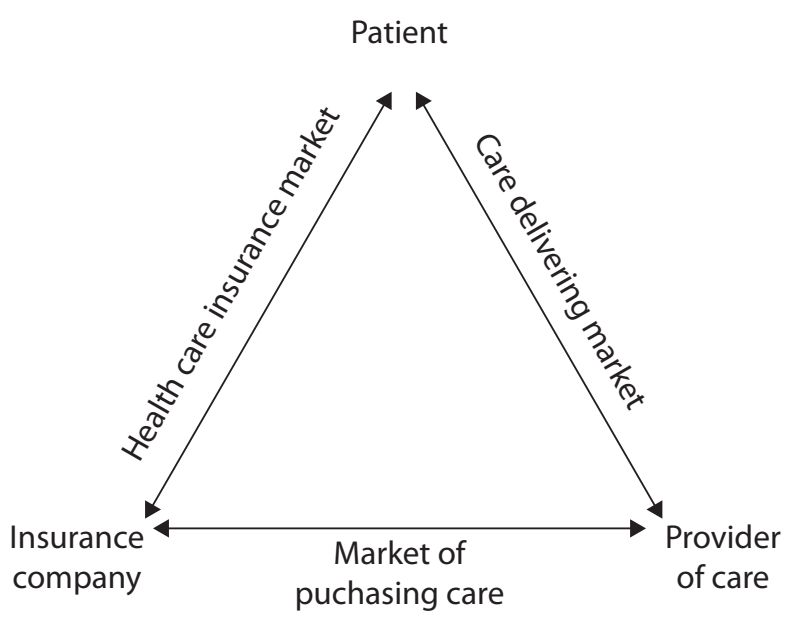

Figure 2. The Dutch Healthcare system (Van der Kraan, 2006). 
government also sets safety and quality standards and controls them by the Inspectorate.

The triangle points out that different submarkets exist, but also notices that different logics or ratio's exists. These three are (WRR, 2004; Van der Kraan, 2006):

- Institutional logic: a legislative system of procedure and rules to coordinate and manage the sector.

- Provision logic: professionals and management take care of the primary process: providing health care services.

- The logic of demand: the needs or demands of clients/ customers, as well as their wishes.

The new insurance system in 2006, under the new Health Insurance Act (Zorgverzekeringswet), obliged all residents of the Netherlands to take out a health insurance. The new system is a private health insurance with social conditions. Private health insurance companies operate the system and the cannot exclude residents in their area of activity. A system of risk equalisation enables the acceptance obligation and prevents direct or indirect risk selection. By melting away the previous difference between people insured via national health funds and those that are insured privately, the healthcare consumer has been given the central role of primary stakeholder. This does not just bring along more opportunities, but also responsibilities.

\section{The organisation of Dutch hospitals}

Dutch hospitals have a clear position in the triangle presented above. Of course they form a group of providers and we will outline this a little more.

Dutch hospitals are categorized in university medical centers, top clinical hospitals and general hospitals, with large differences between them. The university medical centers are linked with a university and together they are responsible for the education/training of doctors and research \& development. Top clinical hospitals are specialised in certain medical areas or treatments. Education and research about these topics also take place within the top clinical setting. One can think about neurosurgery or coronary diseases. The general hospitals deliver basic care and most of the time all different types of specialists are represented.

The legal position of hospitals used to be very easy. For recent years all hospitals were foundations. Main reason for this was that in the 19th century churches founded the hospitals. Nowadays, due to new legislation, also partnerships have been set up, which made it possible for entrepreneurs to enter Dutch health care. They do so by financing new activities of current care providers or by starting their own business in the sector. As a result the Dutch hospital system new faces some privately held hospitals. And although the legal position between hospitals may vary, they are still situated in society and have to be accountable for their actions to society.

In Dutch hospitals all caregivers - like nurses - are on the payroll of the organization, except the medical specialists in (most of) the top clinical and general hospitals. They are generally linked to the hospital trough a civil partnership. They practice their profession for their own risk and account and they all have an individual contract with the hospital. Specialists with the same profession are gathered in a partnership. From a network perspective this is an interesting point, because this means that 'just' running a hospital in fact is running a network in which at least two actors participate.

A small board of directors governs the hospitals. They are responsible for the daily management. The board is monitored by a supervisory board; two tier system. The position of the supervisory board is governed by statutes. Within the hospitals the involvement of medical specialist is arranged by the board of medical staff. This board consists of a formalized delegation of specialists. They work closely together with the board of directors. Indirectly, the specialists are also responsible for the organisations policy. But as we have shown in the first section of this paper, this situation is neither always obvious, nor without tension or problems. Before we focus more on the governance implications of the hospital systems, we will elaborate on the main developments related to the health care system and to hospital organization.

\section{The demands on future healthcare}

That the Dutch health care sector has an outstanding track record can be underpinned with OESO health data. In 2008 the OESO presented that life expectancy of a newborn in the Netherlands was 79.8 years, almost a year above the OESO-average (http://www.oecd.org). The past 25 years the average of years lived in good health has increased from 60 to 65 years. And with an infant mortality rate of 4.4 per 1000 newborns, the Dutch are almost 1 percent under the OESO-average. Compared to other health care systems, the Dutch system can count on lots of appraisal (e.g. Seddon, 2008; Grol, 2007).

Besides these statistical information, we live in dynamic times with some impressive and remarkable changes. For instance, the changing composition and demographic distribution of our population, the increase in chronic diseases and the expanding shortage of labour force in health care are all of great influence in healthcare. The Netherlands currently has over 16.3 million inhabitants. 4.3 million people are over 45, 1.7 million are over 65 and 
nearly 600.000 are 80 years or older. Estimations are that by the year 20256 million people will be over 55 .

Because of this ageing society, the number of people with a chronic disorder will also increase. For instance the increase in the number of patients with heart failure between 2003 and 2025 is $47 \%$, of which $40 \%$ can be directly attributed to an ageing society. The amount of inhabitants in the Netherlands that will suffer a stroke will rise with 30\% in 2020. These are all medical conditions for which dedicated personnel is vital. The potential working population is however decreasing. To clear the shortage, 700,000 additional manpower will be necessary over the next decades, ceteris paribus. Comparatively, we currently have about 1 million people employed in the healthcare sector.

\section{Healthcare reforms}

Taking the above into account, it is evident that the Dutch healthcare system faces some major challenges. Or to put it differently, without drastic changes the system will not be able to meet the demands for health care in future decades. The general belief was that market orientation would improve the healthcare system by inducing competition and by creating alternative options making it possible to choose. The quality and efficiency would improve substantially. Two major interventions took place over the last three years bringing about a lower growth rate of the money spent on health care, while simultaneously shortening the waiting times. This was augmented, as of January 2006, by the introduction of a new insurance system for curative healthcare.

Secondly, in combination with the aforementioned introduction of market orientation, a new payment system in hospital care was introduced, the so-called DBCsystem. Several years ago the financial par of the system was known for its lump-sum approach. Hospitals and medical specialists would receive a fixed budget based on the estimations of performances for that upcoming year. The budget was divided into two separate flows: one for the hospital, the other for the medical specialists. This system changed gradually after 2006 . The DBC-system ${ }^{1}$ intends to introduce new incentives and create a system that is more dynamic than the old budget system. The DBC typifies a patient's illness or affection and is a reflection of hospital's and physician's actions. The insurance company reviews a DBC as the total range of provided care to a patient. All the DBC's are standardized and related to a historical average.

\footnotetext{
${ }^{1}$ The DBC-system can best be described as a typical Dutch version of the classical DRG system.
}

Example:

You suffer from your injured knee. Your family doctor orders you to make an appointment with the orthopedic in a hospital. He first checks your knee in an outpatient clinic. One week afterwards you return for surgery. For recovery you have to stay for two days in the clinic.

Regarding this situation you (your insurance company) need(s) to pay for the following DBC:

'Reference/Orthopedic/Knee/Surgery with clinical stay $^{2}$

Care providers are stimulated to innovate and improve their quality of care continuously. Currently medical specialists receive their salary from a pay per performance principle. Hospitals, partly receive a fixed amount and partly a variable amount. The idea of variability and being reimbursed for performed treatments corresponds with the idea of market orientation and thus competition.

\section{Trends in society}

Beside the changes in hospital settings and the Dutch health care system, society is also changing. The Dutch SCP (national governmental research agency on social cultural issues) has highlighted the specific social and cultural changes in the Netherlands (SCP, 2000). We describe them briefly, because a changing society affects the hospitals and the physicians working in them. The SCP arranges the changes in society along five main trends:

- Individualisation: the main characteristic of this trend can be seen in the increasing importance one denotes to make his or her own decision. It is not so much about what this decision is, but more about the 'freedom' to make own choices. Another point in which individualisation shows is that one asks more and more for custom made service, also in hospitals. What is good for someone else is not necessarily good for me.

- Informal relationships: recent years the physician's white coat radiates his stature. This automatically gained stature is diminished. Differences between people are no longer automatically determined by social status or profession, but are nowadays about personal preferences. To gain respect and status, like a doctor, he or she must work hard to gain this from a patient.

- Informatics: computerizing is the basic for this trend and the rise of the Internet has speeded up this trend. The use of ICT stimulates new services, also in hospital

\footnotetext{
${ }^{2}$ This DBC automatically includes outpatient clinic.
} 
care: e-health, which makes 24/7-acces to a care provider possible.

- Internationalisation: this trend has everything to do with crossing borders in a physical, social, political, economical and cultural way. An example of this in a hospital setting is the accumulating amount of foreign physicians that work in Dutch hospitals. It also shows in cooperation between the Dutch university medical center of Maastricht and the German university medical center of Aachen.

- Intensify: this trend has everything to do with the way one encounters his experiences. It is an evident trend that also reflects in a hospital situation. Ones personal feeling of a treatment is more crucial than ever. Patient empowerment, hospitality and Planetree are several concepts that respond to this trend.

In addition to specific developments in the hospital sector some social developments also affect the medical specialists' autonomy. The aforementioned five elements, which demonstrate the societal changes, also apply in healthcare. The importance of governance increased as a result of these changes; taking and accounting for the responsibility does not allow shielding. Therefore the professional space to act and operate has diminished.

\section{The consequences for hospitals and medical specialists}

We have earlier denoted the special relationship between (most of) the Dutch hospitals and their physicians.

Physicians play an important role in hospital activities. To be efficient as well as effective the hospitals' and the physicians' values and demands should be aligned as much as possible. We notice however that physicians usually feel limited responsibility for the continuity of the hospital they work for. This responsibility can be seen as their commitment to the hospital they work for. Responsibility in this, is a psychological state of a physician that links him to the hospital, e.g. in decision-making and determining strategy. Given the future demands, described earlier, one can think of a rise in the tension between physicians and hospital boards. The trend of internationalisation can be used as an example for this. Given the fact that the Dutch healthcare system faces a scarcity of physicians, foreign medical specialists tend to work in Dutch hospitals. This results in a situation in which the native physicians will see the boards as aggressor and tension rises: this is because the board allows the foreign doctors to come work in their hospital. Another example in this is about the future hospital's portfolio. Due to procedures and regulations about quality and safety, one can think of a system in which not every hospital will perform every type of surgery or will offer every kind of health care service. From this point of view the discussion in the Netherlands has started about childbirth and the presence of a 24/7 surgery team. How will physicians react when one of their specialities is taken away? The tension between physicians and a hospital board also figures from the network approach as we have concluded earlier. One of the most common triggers for network tensions or problems is caused by the divergent views and interests of network partners.

The reforms of the Dutch system, towards a more market orientation and the introduction of the DBC system, have had a tremendous impact on the Dutch healthcare system. Currently, 34\% of the hospital budget is being paid through this DBC-system. This percentage is said to become $100 \%$, which is considered to be a complete market orientation. However, the first results of this transition are already surfacing, bringing about new problems and raising new questions. One of the most important questions relates to the financial position of hospitals and that of the physicians working in them. More specific, the total expenditures on health care have shown an unacceptable rise.

In reaction to this, the Dutch government also prepares new changes. These also accounts for safety and quality, based on the recent incidents in Dutch hospitals (such as the one described in the introduction). There is no reason to believe that this is any different in other Western countries, where the same focus is chosen. As a result, safety and quality of Dutch healthcare have become a high priority issue of national proportions more than ever before. In a recent letter, the Dutch minister of Health, Welfare and Sports pointed out 10 clearly defined issues that should be improved before 2012 (department of VWS, 9 July 2009). Some of the proposed aspects influence the medical specialist directly and can be seen as a direct reaction to the financial position of the physicians.

Given the changing attitude in society and the proposals in the minister's letter, it seems that faith in the Dutch medical specialists is no longer naturally present: it is questioned whether medical specialists should become employees, their wages should be diminished with $20 \%$ and there must be a strong focus on malfunctioning doctors. This conclusion shows an interesting contradiction. On one hand the government and the minister argue to have faith in our professionals, yet the government counters any incident with (new) measures of control.

For the nearby future further changes in the system will take place, Given the specific situation and the way network partners in the hospital go along, it is not questionable whether or not this will give new problems. Good governance therefore is also needed. 


\section{The legitimacy of a hospital's activities}

On one hand, in the current situation - given the two main changes described - hospitals have self-government to a greater extent and thus more autonomy than before. However, on the other hand, the trends in society also influences the extent to which hospitals as well as physicians can operate.

It is therefore a central question in what way hospitals and physicians (together) perform and more how they incorporate public values in their activities. To what extent will hospitals be able to operate without accounting for their affairs? In other words, the legitimacy of third sector organizations - and thus hospitals - is under high pressure due to changes in society as well is in the health care sector. From this perspective, the RMO - a Dutch advising council for the national government on questions regarding social infrastructures - recently stated that third sector organizations need to be deep-rooted in society. This strong connection with society is an essential condition for hospitals to provide good services. Because of this, the RMO suggests that hybrid organizations should invest much more in the relationships with society and civilians (RMO, 2009).

These changes, along the five I's mentioned before, also affect professionals, such as medical specialists in hospitals. The main consequence seems to be that the margin for a medical specialist to operate, as well as his license to operate, have become smaller and more arbitrary. They tend to lose autonomy. The classical approach to professionals, based on autonomy in strongly marked areas, is no longer considered sufficient. Because of social changes professionals are artificially forced to adept. They have to show their operational excellence, have to be accountable and meet expectations of shareholders. It is as Noordegraaf (2007) states: 'In public domains, fuelled by businesslike and market-driven managerialism, professionals have become part of large-scale organizational systems.' The consequence of the diminishing autonomy for physicians is that it affects their network power. As shown before, the contradictions they face with hospital boards are increasing and the government tries to control physicians more and more. The question is what their role and position will be in hospital networks, when their autonomy is worth less than it was years ago? What new position do physicians have to take to stay put? In what way can they be effective in being a doctor as well as being effective in de hospital's policy in future choices?

Managerial influences can not only be seen at the boundaries of medical professional areas, but also in their day-to-day business external influences occur. It can be seen as an effect of the so-called individualisation-trend in society, which makes medical specialists to act more as 'coaches' or 'mentors'. Nowadays clients check the Internet for medical information on clinical pictures, treatments and effective medicine, which gives them another position in information than years ago. Confronted with an opposing opinion from a medical specialist, they question his professionalism, thus leaving medical specialists to the strained task of defending their own actions. High-tech turns into high-touch and a doctor's empathic skills contribute to give meaning to a patient's life. Given a network in which patients play a crucial role and taking into account their decisive position in governance, this is an interesting development.

Each of both developments mentioned above, put a high demand on the situational intelligence of medical specialists. However, it also brings forward a dilemma. On one hand the professional needs freedom to operate and to meet a client's personal expectations. On the other hand, this margin is reduced by the government, because of all the procedures and specific rules introduced by policymakers. In other words, it is necessary to (re)determine appropriate behavior as a consequence of a changing environment, while it is the same environment that limits this behavior. It is the professional's challenge to gain a patient's trust, even in a low-trust society. If not, the physicians' position in the hospital network is fading.

The next point involves management. Due to the businesslike managerialism, also known as New Public Management, the professional and the management domain, slowly appear to come together. It is interesting to see that both parties slowly get used to each other presents. As a result of the interaction of both worlds, managers en physicians understand that they simply need each other. From this overflow in management and professional activities it is also understandable that physicians should have a profound place in networks. This also follows from the central elements of governance presented by the Dutch Health Care Inspectorate (IGZ, 2009) as presented before.

\section{Governance in health care}

It is become apparent that there are multiple actors involved in hospital operations. The hospital seen as a network in itself denotes this. In addition, and form a governance view, it should not only be the board of directors that should manage, control and take accountability for their actions, the medical specialists uphold a similar position, as well as patients, the board of commissioners and other hospital personnel. But also other network participants, such as ICT providers have to take their responsibility. This at least means that every actor in the hospital has its own governance responsibilities. Of course, these individual responsibilities are a share of the total responsibility for hospital governance. However, the distribution of these 
shares is not equal nor is evident. Countervailing power, diverging values and goals, network tension and an ever changing society: good governance in a healthcare network is not as obvious as one would think.

\section{Control or learn}

In a background study the Erasmus University Rotterdam (2009) presented a framework for governance, related to the possible risks or mistakes that can occur. This is useful because it gives an insight in the ways one could take action after a risk took place or how to prevent certain things to happen: good governance.

The central point of this model is that certain risks must be seen in interaction with certain types of governance. There are two types of governance instruments: control and learn. These two types of governance should be applied according to the occurring problem.

The WRR (2008) also denoted four types of risks:

- Simple risks: classical approach of calculating risks, in which the chance and the size are known.

- Complex risks: calculating risks is difficult because of interfering factors that make the result of the calculation uncertain.

- Uncertain risks: these are risks we do not know well enough. Calculation of damage therefore is not possible.

- Ambiguous risks: beside the uncertainty these risks, also involve different opinions on the judgement of the risk.

The articulation of a certain risk being, simple, complex, uncertain or ambiguous is always a result of the institutional context in which this judgment has to be made. In this notion there is a critical element of the study. This institutional context stimulates - due to trends and developments in society - that every incident should be denoted simple. Only than direct action and control measures can be practised. Only when an incident is simple, transparent action that aims for control can be practised. In several cases complex or ambiguous incidents occur, it is societies wish that denote them as simple so direct matters can be taken. The opposite action of learning - which is seen as the proper action in case of ambiguous problems - therefore is set back.

Furthermore it is pointed out that the 'feeling or belief of society' is that internal governance does not function well. The board does not control professionals' work and that is why incidents occur. More directly and hard instruments should improve governance.

Although this tendency is understood, the contrary seems true. Only learning can be the instrument that makes ambiguous incidents over time become simple. One should learn from mistakes, and not be punished. One has to learn in order to prevent it from happening again. The board's position in this is crucial but ambivalent. It is a typical element of a member of the board that he or she can differ between strategic vision and daily operational routine. This ambivalent position is the same in governance: differ between control and learn.

What is interesting about this point of view is the similarity in the ambivalent position of members of the board. Their ability to make strategic choices as well as their operational view on a patient's well being, should help them in balancing with controlling or learning. Besides that, a member of the board should have another crucial capability in order to get along with this ambivalent position in governance: empathy. As a starting point, for this, one can see learning as if it is a way of giving trust. Learning is a positive way of control. Stated the other way around, control has a negative connotation, while learning intrinsically has a positive connotation. Learning is about to trust employees, physicians or even network participants that they will do better next time. This means responsibilities stay where they belong, and one is stimulated to act with more precaution the next time, or will take into account other matters when deciding what to do. The control option will result in the opposite. But what is crucial for a member of the board to trust people, is that one can not do without a 'soft' approach. Only an empathic behaviour will do in such a case. Learning in this is a positive way of control, is about trust, about sensitivity and about empathy.

Although, the former may lead to the conclusion that learning is seen as the only appropriate action, it is not desired that learning is the only instrument. Both, control and learning should exist next to each other. It is the board's obligation and should be a core-capability to differ between both instruments along the real 'value' of the incident. However, what is crucial is that the learning-instrument is given a true opportunity, also when this is hard, takes time and needs courage.

\section{Governance and physicians}

Given the last paragraph of instruments for governance and the notion that both board and physicians play an important role in governance, as explained by the Inspectorate, we take a closer look at the governance relation between these two actors. Because this relation is vital for the hospitals' performance, it is given special attention before we focus on networks wider.

First we give some typical examples of the (im)possibilities of governance between hospital boards and the physicians. The Dutch healthcare sector has a complex system of education for medical specialists. One of the characteristics is the way graduated students specialize to become a medical specialist. They do so, by co-working in a hospital under 
supervision of an experienced medical specialist. This means, that the profession is a closed system and remains a closed system. This medieval look-a-like system does not allow the outer world to intervene in this profession. In terms of governance, this example is interesting. Nor the government, nor the organizations themselves can influence the capabilities of new medical specialists. It is a self-fulfilling culture.

In most ordinary organizations - meaning not hospital organizations - it is common for employees to have professional dialogue about ones evaluation or appraisal. In medical specialists profession this is developing prudently. The so-called Individual Functioning of Medical Specialists (IFMS) has recently started as a pilot study in eight hospital settings in The Netherlands. The IFMS aims for evaluating and improving a physician's functioning on 8 elements. The systems functions in favour of and by medical specialists (OMS, 2008). But although the system is a good initiative - it tries to open up the closed world of physicians - it has sheer nothing to do with the hospital board and therefore is only indirectly related to good governance.

A last example is more judicial and closely related to the IFMS. Until now it is very difficult for a hospital board to discharge a malfunctioning medical specialist. To improve the situation and to hand over a more powerful instrument to the board, a growing amount of hospitals have adopted the so-called 'code of malpractising medical specialists'. This code leaves the opportunity for investigation by a third party in case of suspicion. What figures from this point is the possibility for a board to take action from a governance point of view. But action can only be taken when the situation is irretrievably lost. The code makes action possible, but only when the 'learning option' is no longer available. This is unfortunate, because the learning option could have been effective earlier in the process of a specialist becoming malfunctioning.

Given the examples prudently some conclusions can be drawn. The governance between board and physicians is not easy. It is hard to enter the professionalism or autonomous position of a specialist in order to be sure whether or not his actions are right, in favour of the patient and also align with the organization's values. The openness that is created with IFMS is still closed for the hospital board and therefore action can only be taken when matters are worse. In relation to the category of risks (WRR, 2008), it may seem that all incidents in which physicians are involved, are denoted simple risks. The contrary is true. Most of the time these risks are ambiguous or very complex. Given the background study of the Erasmus University Rotterdam these specific types of risks should be countered with the learning strategy. As shown, it seems this is hardly possible?
A well performing hospital can be identified by a set of variables. One of these variables is the period of a certain board being in charge. Members of the board who are already for a decade in the board usually have an outstanding relationship with the physicians. It seems this relationship is built upon a personal bond. Most of time this bond is based upon trust. In such situations it looks like bad things do not happen. Of course this is not true, but these situations are handled with care and at the right time. As said the relationship between the board and the physicians is based upon trust and respect. This results in a situation in which both parties respect each other's situations, goals and feel mutual responsible. In other words, two main factors in a hospital's performance and thus in the hospital network, form a stable equilibrium. This is unless both have divergent goals.

When governance as a result of factors like trust, respect, sensitivity and learning contribute to the hospitals' sustainability and stability, should these factors also fit for governance in a network?

\section{Governance in networks}

Governance in networks, specifically those in the health care system, is about accountability and responsibility to all participants: clients, physicians, board, nurses, government insurance companies, etc. Without any doubt the most important party in this is society. The RMO (2009) underpins this idea.

The complexity of the blurred, outside world, cannot simply be overcome by known governance principles, like those proposed in the ministry's letter as referred to earlier or control instruments. The occurred problems are seldom that simple. Otherwise, as stated by the RMO, when society is seen as the moral owner of a hospital: do government's control interventions align with society's values and principles? In other words, do government's actions for control respect the legitimacy of a hospital in society? When this notion is related to the risk classification, it figures that most risks can be addressed ambiguous or complex. And therefore governance should head more for learning instead of control.

By sending out the governance letter, the minister showed his preference. Although the government speaks about trust, their actions show control. This is not in line with what we call society's desire for good governance. The ever-growing list of indicators, to make decisions and actions transparent, does not fit with the classification of the risks. Nor learning, nor trust can be found in the letter referred to. Not for society, not for medical specialists and not for the hospital board. Analyzing the complexity of the Dutch system and the turbulence of a hospital's context, the question 
is whether changing governance structures will solve the existing problems and diminish complexity.

The healthcare sector needs new perspectives, new ideas and new theories of how the outside world complexity can be incorporated in the inside world of the already complex hospitals. This leaves us with the idea of distant government that only sketches a framework on outlines and does not intervene in the hospital's day-to-day action. This means, the government sets a framework and pulls back, leaving a big opportunity and challenge for those involved with decision-making in hospitals. The expectancies seem to be irrealistic, but in the same time are increasing as well. This means that more situations are defined as failures or incidents and the expectancies of the effects of governance are too high. What is said: the government should be able to give trust to the field or to the network and let participants themselves figure things out.

As mentioned before, countervailing power is an important factor that dictates the equilibrium of a network. What is interesting is that this power does not necessarily have to do with values or true power; it can also be a result of trusting each other. Empathy, respect and sensitivity (to 'feel' what is going on a strategic and operational level) are the key elements to retain a network that is based upon mutual trust.

As a result of learning, trust can define the form of coping with the dynamic and complex context; the way it is dealt with in a network. Trust can be a steady factor, but is also a fragile one. On one hand, when a relationship is built on trust, no control is necessary. On the other hand, in situations where control is necessary, it can be seen as 'trust giving' (WRR, 2004). Empathy and sensitivity of participants could foster trust and therefore diminishes the fragile part of it. Empathic network participants 'feel' each other's mood and behaviour and will have a little bit more patience. This patience gives them time: time to learn from mistakes or miscalculated issues and to grow an even better or more stable equilibrium in the network.

\section{Conclusion}

Dutch hospitals increasingly are confronted with a demanding society in terms of taking responsibility and being accountable. Whether it is about hospitals' policy, malfunctioning physicians or their loans, all these issues are considered in relation to public values. Given the hospitals' position in society, feedback from society (clients) is crucial and needs encouragement. Not only from a public value point of view, but also form a governance point of view as shown in the IGZ model. The hospital organization as well as the context of Dutch health care can be considered as a network in which society (clients) holds a strong position.
The central question is 'How can hospitals optimally organise their governance, taking into account the complex field and context in which hospitals operate?'

Dutch hospitals operate in a fast changing and increasingly complex environment. The blurring between market, hierarchy and network principles with their failures, continuously expects a 'flexible' reaction to optimize medical quality and business results. Given all kind of different partners necessary to make a hospital well functioning, it can be referred to as a network that aims for improving efficiency and effectiveness. The hospital in itself is a typical network in which the board and the physicians play a key role, and the patient or society is the most vital partner. It figures that due to lots of reasons varying from social developments and diverging goals of physicians and members of the board - tension is present in the network, and the network equilibrium as well as the countervailing powers are dynamic and complex factors. This leaves a situation in which the hospitals itself can be seen as a network, the hospital sector can be seen as one and the context is blurred as a result of the presence of different paradigms. This is important to consider when governance should be organized?

One can question if changes in systems, structures or procedures are sufficient to accomplish stable network equilibrium. Given the ever changing demands of society, the complexity and dynamics of the networks and of each of the participants' structures and systems seem to be too inflexible to handle demands. Besides that, especially physicians do not feel addressed with these kinds of instruments. They have a better feeling with personal relationships built on trust. Dutch government wants the same, but acts the other way around: they speak about trust but, considering the minister's letter, act with control instruments.

It looks like the properties of networks, including those in health care, do not match changes in inflexible system. When looked at it from another point of view, the same conclusions can be drawn. In accordance with the study of Erasmus University Rotterdam (2009) - control and learning instruments related to types of risks - network problems seldom are simple. Most of the time networks face diverging values and goals and therefore tension results in complex or ambiguous problems. Not withstanding the fact that control can be effective, the learning instruments should have a more profound role.

As a result of that, learning implies good relationships built upon trust. Therefore some central themes to create such should be appointed here. Network participants should open up and lower their shields: they should be more transparent in their goals and means. Closed systems or organizations appeal to secret things to happen and will not built trust. To open up participants should feel free and safe 
to do so. A system based on trust encourages this openness, while learning stimulates this. From this point of view it is understandable that patients (or society) are encouraged tot open up. They are encouraged to give feedback to insurance companies, hospitals and physicians. Their information is crucial for quality of service and for governance as well.

Openness and vulnerability in this are two of a kind. And when talking about organizations to open up, it is always about people to open up. Therefore personal qualities like empathy and sensitivity are crucial.

Governance in a network only on a controlling basis will not sustain for a long time. It is important that the focus moves towards more learning orientated governance in which relationships are key elements. Both lead to a trustworthy network in which mutual responsibility and respect foster good governance.

If we look at the example of the neurologist in the MST hospital one more time, the pressure on the hospital was high, because of society's expectations. Besides that, responsibilities from a governance perspective were not clear and the culture between the main players was a closed one. Because of that, neither of the players acted properly, with the known result. Given the aforementioned points, several patients could have been prevented from damage and needless suffering. The given problem of this hospital was not obvious or easy to tackle, so learning as a governance instrument should have been appropriate.

Is there an optimal organisation of governance conceivable, which can exclude these kinds of mistakes in the future? The answer is 'no'. With rules and a clear organization of control, supervision, justification, accountability and responsibility, a lot of issues can be identified. The key drivers are mutual transparency and openness in expectations and needs, to share responsibilities and to work with respect. Having trust in partners in a learning environment will improve network performance.

\section{References}

Broekman, L. and Th. Camps, 2006. Organisatienetwerken in de zorg: een verkenning. Kluwer, Deventer, the Netherlands.

Caiden, G.E., 1999. The essence of public service ethics and professionalism. In: L.W.J.C. Huberts en J.H.J. van den Heuvel (eds.) Integrity at the public-private interface. Shaker Publishing, Maastricht, the Netherlands, pp. 21-44

Erasmus University Rotterdam, 2009. Veiligheid in de zorg: achtergrondstudie bij de Staat van de Gezondheidzorg 2009. EUR, Rotterdam, the Netherlands.

Galbraith, J.K., 1963. American capitalism: the concept of countervailing power. Penguin Books, Harmondsworth, UK.
Grol, R. and M. Faber, 2007. Commonwealth Fund International Health Policy Survey: onderzoek onder consumenten en patiënten in 7 laden. Centre for Quality of Care Research (WOK), Nijmegen, the Netherlands.

IGZ, 2009. De vrijblijvendheid voorbij: sturen en toezichthouden op kwaliteit en veiligheid in de zorg. Den Haag, the Netherlands.

Jessop, B., 2003. Governance and meta-governance: on reflexivity, requisite variety and requisite irony. In: $\mathrm{H}$. Bang (ed.) Governance as social and political communication. Manchester University Press, Manchester, United Kingdom.

Noordegraaf, M, P.L. Meurs and A. Montijn-Stoopendaal, 2005. Pushed organizational Pulls: Changing responsibilities, roles and relations of Dutch health care executives. Public Management Review, 7: 25-43.

Noordegraaf, M., 2007. From Pure to Hybrid Professionalism. Administration \& Society, 6: 761-785.

RMO, 2009. Stem geven aan verankering: over de legitimering van maatschappelijke dienstverlening. RMO, Den Haag, the Netherlands.

RVZ, 2008. De rol van de farmaceutische industrie. (Achtergrondstudie) RVZ, Den Haag, the Netherlands.

Schrank, A. and J. Whitford, 2007. Varieties of Network Failure. Paper presented at the annual meeting of the American Sociological Association, TBA, New York, USA.

SCP, 2000. Sociaal en cultureel rapport 2000; Nederland in Europa. SCP, Den Haag, the Netherlands.

Seddon, N., 2008. Is the future Dutch? The Lancet, 372: 103-105.

Van de Donk, W.B.J.H., 2001. De gedragen gemeenschap: over katholiek maatschappelijk organiseren de ontzuiling voorbij. SDu, Den Haag, the Netherlands.

Van der Kraan, W.G.M., 2006. Vraag naar vraagsturing: een verkennend onderzoek naar de betekenis van vraagsturing in de Nederlandse gezondheidszorg. Optima Grafische Communicatie, Rotterdam, the Netherlands.

Van der Wal, Z. and E.J.Th. van Hout, 2009. Is Public Value Paramount? The Intrinsic Hybridity and Multiplicity of Public Values. International Journal of Public Administration 32: 220231.

Van der Wal, Z., E.J.Th. van Hout, A.J. Kwak and M. Oude-Vrielink (eds.), 2007. Managers en Professionals. Waarden in een hybride praktijk. Bestuurskunde. 16: 2-52.

Van Hout, E.J.Th., 2007. Zorg in spagaat: management van hybride, maatschappelijke organisaties. Lemma, Den Haag, the Netherlands.

WRR, 2004. Bewijzen van goede dienstverlening. Amsterdam University press, Amsterdam, the Netherlands.

WRR, 2008. Onzekere veiligheid. Een pleidooi voor probleemgerichte politiek. Amsterdam University press, Amsterdam, the Netherlands. 
